\title{
Citric Acid Promotes the Mobilization of Phosphorus under the Lower Concentration of Low Molecular Weight Organic Acids in Acidic Forest Soil
}

\author{
He Zhu $(\mathbb{D}$, Haijian Bing, and Yanhong Wu \\ The Key Laboratory of Mountain Surface Processes and Ecological Regulation, Institute of Mountain Hazards and Environment, \\ Chinese Academy of Sciences, Chengdu 610041, China
}

Correspondence should be addressed to Yanhong Wu; yhwu@imde.ac.cn

Received 23 September 2021; Accepted 3 January 2022; Published 20 January 2022

Academic Editor: George Kyzas

Copyright (c) $2022 \mathrm{He}$ Zhu et al. This is an open access article distributed under the Creative Commons Attribution License, which permits unrestricted use, distribution, and reproduction in any medium, provided the original work is properly cited.

\begin{abstract}
Low molecular weight organic acids (LMWOAs) secreted by plant roots enhanced the release of inorganic $\mathrm{P}(\mathrm{Pi})$ and organic $\mathrm{P}$ (Po) into the soil solution and thereby increased plant-available Pi in soils. Not the effect of LMWOAs on inducing organic $\mathrm{P}$ (Po) released into soil solution through soil microorganisms at different temperatures was poorly understood, but the transform mechanism for $\mathrm{P}$ fraction was also not well explained. This study used three experiments to determine the release of $\mathrm{P}$ and the transformation mechanism of $\mathrm{P}$ fractions induced by oxalic acid, citric acid, and malic acid in acidic forest soils. The results showed that LMWOAs, as carbon sources for microorganisms, mobilize Po more effectively than glucose. Inorganic $\mathrm{P}$ and organic $\mathrm{P}$ were released by LMWOAs followed by oxalic acid > citric acid $>$ malic acid if the substrates of P and LMWOAs were enough. There may be a critical threshold for the concentration of citric acid and oxalic acid between $10 \mathrm{mM}$ and $25 \mathrm{mM}$ to require for the solution of adsorbed and precipitated P, respectively. In all, LMWOAs increased the concentration of labile $\mathrm{P}$ by decreasing the concentration of stable P. The results indicated that LMWOAs can significantly promote $\mathrm{P}$ availability in acidic forests soils, and the effect of microorganisms on soil available $\mathrm{P}$ was more inclined to use LMWOAs than glucose.
\end{abstract}

\section{Introduction}

Phosphorus (P), as an essential element for plant growth, often limits the primary productivity of global terrestrial ecosystems [1]. Although the content of total P (TP) in the soil is very high (usually between 50 and $1500 \mathrm{mg} / \mathrm{kg}$ ), soil available forms of inorganic $\mathrm{P}$, which is directly absorbed and utilized by plants, only account for a small part of the soil TP in most soils [2-4]. For example, although the average available form of inorganic $P$ extracted by resin in global natural soil is $17.2 \mathrm{mg} / \mathrm{kg}$ (accounting for $4.12 \%$ of the TP), its proportion is not invariable $[5,6]$. Therefore, it is essential to explore the variation of soil $\mathrm{P}$ solubility and its driving factors for further understanding the strategies of plants to cope with the spatial variations of $\mathrm{P}$ deficiency and $\mathrm{P}$ limitation of primary productivity in terrestrial ecosystems $[7,8]$.

When the content of $\mathrm{P}$ in soil is deficient, plants can release low molecular weight organic acids (LMWOAs) through their physiological strategies to increase the amount of soil bioavailable P (Bio-P) in the soil [9]. Previous studies have shown that LMWOAs can effectively increase the release of inorganic $\mathrm{P}(\mathrm{Pi})$ in the soil, thus, increasing the concentration of Bio-P in the soil $[10,11]$. It has been widely speculated that LMWOAs enhance the mobilization of soil inorganic $\mathrm{P}$ through (1) directly promoting the dissolution of sparingly soluble minerals containing $\mathrm{Pi}$, (2) shifting $\mathrm{pH}$ and chemical equilibria in soil solution, (3) altering the surface characteristics of mineral particles or occupying ligand exchange surface, and (4) forming complexes with $\mathrm{Fe}^{2+}$, $\mathrm{Al}^{2+}$, and $\mathrm{Ca}^{2+}$, thus, blocking $\mathrm{P}$ adsorption sites on soil particles [12-14]. Moreover, LMWOAs may enhance the release of organic $\mathrm{P}$ (Po) bound to soil minerals. However, the mechanism for Po release induced by LMWOAs is not well explained, especially for soils with contrasting physicchemical properties (e.g., $\mathrm{pH}, \mathrm{Fe}-/ \mathrm{Al}$-oxide, and Ca-carbonate) similar to inorganic $\mathrm{P}$, which may affect Po release from 
soil because $\mathrm{Fe}, \mathrm{Al}$, and $\mathrm{Ca}$ oxides are the main soil minerals that affect the solubility of soil P. Fe and Al oxides play a leading role in acidic soil, while Ca oxides play a leading role in alkaline soils [4]. Although organic P needs to be mineralized to be absorbed by plants, it is an important component of TP and a potential source of Bio-P $[15,16]$. Coincidentally, LMWOAs are important carbon sources for microorganisms, which play an important role in the mineralization of organic P. Hence, the effectiveness of mobilization depends on the soil type and the chemical structures and concentrations of LMWOAs [17]. Consequently, knowledge of the different $\mathrm{P}$ fractions can be used to directly determine the P pools acted upon by LMWOAs and deduce the mechanisms of $\mathrm{P}$ transformation.

To address these issues, to better study the effect of LMWOAs on the variations of $\mathrm{P}$ fractions and the mobilization of soil bioavailable $\mathrm{P}$ in soil, this study set up three groups of experiments to study these phenomena. First, both LMWOAs and glucose affect the transformation mechanism of $\mathrm{P}$ fractions as carbon sources for microorganisms, considering whether microorganisms play a role of organic $\mathrm{P}$ in this mechanism at different temperatures. Second, to verify the ability of different concentrations of LMWOAs to activate inorganic $\mathrm{P}$ and the threshold affecting its ability between different LMWOAs. Lastly, the objective of this study was to study the impact of three common LMWOAs (oxalic acid, citric acid, and malic acid) on the kinetics of Pi and Po release in acidic soils. In all, we hypothesized that both LMWOAs and glucose can act as carbon sources to affect the transformation of $\mathrm{P}$ fractions through microbial mineralization. In addition, our hypothesis is that LMWOAs will increase the rate of the kinetics of both Pi and Po release than water, and citric acid will be the most effective reagent for increasing the rate of $\mathrm{Pi}$ and Po release into soil solution of acidic soils.

\section{Materials and Methods}

2.1. Soil and Organic Acids. Surface layers $(0-20 \mathrm{~cm}$, removing the litter layer) of the soil were collected at $3000 \mathrm{~m}$ a.s.l. in August 2018 in Gongga Mountain $\left(29^{\circ} 20^{\prime}-30^{\circ} 20^{\prime} \mathrm{N}\right.$, $101^{\circ} 30^{\prime}-102^{\circ} 15^{\prime} \mathrm{E}$ ), located in the southwest of China at the southwest edge of Tibetan Plateau with an elevation $7556 \mathrm{~m}$ a.s.l. The parent materials are dominated by granites, ordering feldspar $(43.7 \%)>$ quartz $(32.7 \%)>$ hornblende ( $17.9 \%)>$ chlorite $(4.9 \%)>$ muscovite $(0.8 \%)$ [18]. The specific types of soil and vegetation with altitude have been described by Bing et al. [19] and Zhou et al. [18], and the same vegetation type (Abies fabric) and bedrocks on the Mt. Gongga were found from $2700 \mathrm{~m}$ to $3600 \mathrm{~m}$ a.s.l. The collected soil samples were air-dried and passed through a $2 \mathrm{~mm}$ sieve before experimental design. The LMWOAs selected for this study were oxalic acid, citric acid, and malic acid because of their widespread natural occurrence in soils in Mt. Gongga [20].

\subsection{Experimental Designs}

2.2.1. The Effects of Temperature on the Mobilization of Bio$P$ in Soil by LMWOAs. Soil $(2 \mathrm{~g})$ was placed in $50 \mathrm{~mL}$ centri- fuge tubes and added deionized water (control), organic acids, and glucose solution was added to each tube (containing $10 \mathrm{mmol} \mathrm{kg}^{-1}$ soil of citric acid, malic acid, oxalic acid, or glucose). Combined with the concentrations of three kinds of LMWOAs in soil, the mobilization experiments of Bio-P by LMWOAs were carried out at different temperatures $\left(4^{\circ} \mathrm{C}, 14^{\circ} \mathrm{C}\right.$, and $\left.24^{\circ} \mathrm{C}\right)$. In this study, the experimental temperature gradient was set at $14^{\circ} \mathrm{C}$ at $3022 \mathrm{~m}$ in the growing season (August). The minimum temperature was set at $4^{\circ} \mathrm{C}$ in the progrowing season (May) to restrain the microbial metabolism activity, and the maximum temperature was set at $24^{\circ} \mathrm{C}$ to verify the mobilization effects of LMWOAs and microbial metabolism activity on the release of $P$. The soil moisture content was set at $70 \%$ of its maximum field capacity. Under the corresponding temperature conditions for 15 days, it was weighed every day to keep the soil moisture content unchanged. After incubation for 15 days, the soil was collected from the centrifuge tube and dried in an oven $\left(40^{\circ} \mathrm{C}\right.$ for $\left.72 \mathrm{~h}\right)$ for subsequent $\mathrm{P}$ component analysis.

2.2.2. The Effects of Concentrations on the Mobilization of Bio-P by LMWOAs. According to the existing studies, the higher the concentration of LMWOAs, the stronger their ability to activate $\mathrm{P}$ in soil. Combined with the concentration of LMWOAs observed in situ, the concentration gradient of LMWOAs in this experiment was set to 6 gradients $(0,5,10$, 25,50 , and $100 \mathrm{mM}$ ) to study the amount of $\mathrm{P}$ mobilization at 1 hour. Hence, soils $(2 \mathrm{~g})$ were placed in $50 \mathrm{~mL}$ centrifuge tubes, and then $20 \mathrm{~mL}$ of deionized water (control) or $20 \mathrm{~mL}$ of organic acid solution was added to each tube. Meanwhile, two drops of toluene were added to inhibit microbial activity before capping the tubes. The suspensions were shaken on an end-to-end shaker (200-cycles $\min ^{-1}$ at $24^{\circ} \mathrm{C}$ ) for 1 hour, centrifuged at $12,000 \mathrm{~g}$ for $10 \mathrm{~min}$, and filtered through Whatman filter paper (no. 42). The filtered suspensions were used to measure the release of Pi by LMWOAs.

2.2.3. The Effects of LMWOAs at a Different Time on the Mobilization of Bio-P. LMWOAs with $100 \mathrm{mM} \mathrm{kg}^{-1}$ concentration were selected for the experiment according to the experimental design 2.2.2. The reason was that, compared with other low concentrations of LMWOAs, the LMWOA concentration of more than $100 \mathrm{mM}$ in the soil can better reflect the mobilization of LMWOAs from soil P. Soils $(2 \mathrm{~g})$ were placed in $50 \mathrm{~mL}$ centrifuge tubes, and then $20 \mathrm{~mL}$ of deionized water (control) or $20 \mathrm{~mL}$ of organic acids solution was added to each tube. Meanwhile, two drops of toluene were added to inhibit microbial activity before capping the tubes. The suspensions were shaken on an end-toend shaker $\left(200\right.$-cycles $\min ^{-1}$ at $\left.24^{\circ} \mathrm{C}\right)$ for $5,10,15,30,60$, $120,240,480,960,1,440$, or $2,880 \mathrm{~min}$, centrifuged at $12,000 \mathrm{~g}$ for $10 \mathrm{~min}$, and filtered through Whatman filter paper (no. 42). The residues were washed three times with deionized water to completely remove the residual low molecular weight organic acids. The suspensions were used to measure the release of Pi and Po by LMWOAs. The soil was collected into centrifuge tubes that were shaken for $2,880 \mathrm{~min}$, rinsed, and dried $\left(40^{\circ} \mathrm{C}\right.$ for $\left.72 \mathrm{~h}\right)$ for subsequent 
P fractionation analysis. Three replicates were set for all experimental treatments in our study.

2.3. Soil P Fractions. The extractions of $\mathrm{P}$ fractions were performed by using the modified Hedley methods [21]. Briefly, approximately $0.5 \mathrm{~g}$ dry soils were successively extracted by the anion-exchange membrane, $0.5 \mathrm{M} \mathrm{NaHCO}_{3}(\mathrm{pH}=8.5)$, $0.1 \mathrm{M} \mathrm{NaOH}$, and $1 \mathrm{M} \mathrm{HCl}$. The extracted P fraction was designated as a resin- $\mathrm{Pi}, \mathrm{NaHCO}_{3}-\mathrm{P}, \mathrm{NaOH}-\mathrm{P}$, and $\mathrm{HCl}-\mathrm{P}$. For $0.5 \mathrm{M} \mathrm{NaHCO}_{3}(\mathrm{pH}=8.5)$ and $0.1 \mathrm{M} \mathrm{NaOH}$ extract, the total $\mathrm{P}\left(\mathrm{NaHCO}_{3}-\mathrm{Pt}\right.$ and $\left.\mathrm{NaOH}-\mathrm{Pt}\right)$ was measured by digesting the solution with $0.9 \mathrm{M} \mathrm{H}_{2} \mathrm{SO}_{4}$ and ammonium persulfate. $\mathrm{NaHCO}_{3}$-Po and $\mathrm{NaOH}$-Po were measured as the difference between undigested and digested. The concentrations of $\mathrm{P}$ were measured by the UV-vis spectrophotometer (SHIMADZU UV 2450) using the phosphomolybdate blue method [22]. The sum of resin- $\mathrm{Pi}, \mathrm{NaHCO}_{3}-\mathrm{Pi}$, and $\mathrm{NaHCO}_{3}-\mathrm{Po}$ was defined to be the fraction of bioavailable $\mathrm{P}$ (Bio-P). Finally, the remaining residual soil $\mathrm{P}$ was determined by digestion in boiling concentrated $\mathrm{H}_{2} \mathrm{SO}_{4}$ with repeated addition of $30 \% \mathrm{H}_{2} \mathrm{O}_{2}$.

2.4. Statistical Analysis. Soil P fraction data were subjected to normality and homogeneity tests before analysis of variance (ANOVA) using SPSS. Significant differences $(P<0.05)$ in the concentration of each P fraction before and after shaking with each treatment solution (water, citric acid, oxalic acid, malic acid, and glucose) were evaluated with a one-way analysis of variance (ANOVA) for each soil studied. All statistical analysis in this study was performed by the software package SPSS 19.0 and Origin 2017 for Windows.

\section{Results}

3.1. The Effects of Temperature on the Mobilization of Phosphorus by LMWOAs. The results showed that different kinds of LMWOAs had different effects on P fractions at different temperatures. LMWOAs promoted, unchanged, or inhibited the process of $\mathrm{P}$ fractions at different temperatures (Figure S1). The results showed that LMWOAs changed the concentrations of other $\mathrm{P}$ fractions by reducing the residual $\mathrm{P}$ at $4^{\circ} \mathrm{C}$ (Figure $1(\mathrm{a})$ ). For example, only oxalic acid significantly increased the concentration of resin-P compared with deionized water, glucose, and other two organic acids at $4^{\circ} \mathrm{C}$. Oxalic acid increased the concentrations of $\mathrm{NaHCO}_{3}-\mathrm{Po}$ and $\mathrm{NaOH}-\mathrm{Po}$, thus, increasing the concentration of $\mathrm{NaHCO}_{3}-$ $\mathrm{Pt}$ and $\mathrm{NaOH}-\mathrm{Pt}$. Citric acid increased the concentrations of Bio-P and reduced the concentrations of $\mathrm{NaOH}-\mathrm{Pt}$, $\mathrm{HCl}-\mathrm{P}$, and residual P. However, malic acid did not change the fractions of Bio-P and other $\mathrm{P}$ fractions compared with oxalic and citric acids. LMWOAs inhibited the concentration of resin- $\mathrm{P}$ in the soil at $14^{\circ} \mathrm{C}$ but increased the concentration of Bio-P by increasing the concentration of $\mathrm{NaHCO}_{3}-\mathrm{Pt}$ (Figure 1(b)). Oxalic acid increased the concentration of $\mathrm{NaHCO}_{3}-\mathrm{Po}$ and $\mathrm{NaOH}-\mathrm{Po}$, thus, increasing the concentration of $\mathrm{NaHCO}_{3}-\mathrm{Pt}$ and $\mathrm{NaOH}-\mathrm{Pt}$. Citric acid mainly reduced the concentration of $\mathrm{NaOH}-\mathrm{Pt}, \mathrm{HCl}-\mathrm{P}$, and residual $\mathrm{P}$ at $14{ }^{\circ} \mathrm{C}$. Malic acid reduces the concentrations of $\mathrm{NaHCO}_{3}-\mathrm{Po}$ and $\mathrm{HCl}-\mathrm{P}$, thus, increasing the Bio-P frac- tions. The three kinds of LMWOAs showed similar characteristics in changing $\mathrm{P}$ fractions at $24^{\circ} \mathrm{C}$ (Figure $1(\mathrm{c})$ ). All three LMWOAs significantly increased the concentration of Bio-P and decreased the concentrations of $\mathrm{NaOH}-\mathrm{Po}$, $\mathrm{NaOH}-\mathrm{Pt}$, and HCl-P. In all, LMWOAs increased the concentration of Bio-P mainly through increasing the concentrations of $\mathrm{NaHCO}_{3}-\mathrm{Pi}$. And significant variations of organic $\mathrm{P}$ were observed in higher temperatures.

3.2. The Effects of Concentration of Soil Inorganic $P$ by LMWOAs. The mobilization ability of inorganic $\mathrm{P}$ was different from the various concentrations of LMWOAs in soil, showing that the higher concentration of LMWOAs had the greater mobilization ability of inorganic $\mathrm{P}$ in soil (Figure 2). With the increasing concentrations of LMWOAs, the release of inorganic $\mathrm{P}$ showed a linear increasing trend (Figure 2). Oxalic acid has the strongest mobilization ability, followed by citric and malic acids. However, with different concentrations of LMWOAs, different kinds of LMWOAs have different abilities to liberate soil $\mathrm{P}$ at 1 hour. The results showed that when the concentration of LMWOAs was lower than $10 \mathrm{mM}$, the mobilization ability of citric acid and malic acid was greater than that of oxalic acid, while the mobilization ability of oxalic acid was significantly enhanced when the concentration of LMWOAs was higher than $25 \mathrm{mM}$ compared with citric acid and malic acid (Figure 2).

3.3. Kinetics of $P i$ and Po Release and Variation of $P$ Fractions by the Effects of LMWOAs. The results showed that soil inorganic $\mathrm{P}$ and organic $\mathrm{P}$ in soil were released by the influence of LMWOAs with the increase of time (Figure 3). Three kinds of LMWOAs rapidly released inorganic $\mathrm{P}$ and organic $\mathrm{P}$ in a short time, but the release rate slowed down with the increase of time. Specially, oxalic acid had the fastest mobilization rate, citric acid and malic acid had less mobilization rate for inorganic $\mathrm{P}$ than oxalic acid, and deionized water had no obvious mobilization rate for inorganic P. Inorganic P was released by deionized water and LMWOAs followed by oxalic acid $(26.88 \mathrm{mg} / \mathrm{kg})>$ citric acid $(21.27 \mathrm{mg} / \mathrm{kg})>$ malic acid $(9.51 \mathrm{mg} / \mathrm{kg})>$ deionized water $(1.56 \mathrm{mg} / \mathrm{kg})$ after 48 hours. Like the variation of LMWOAs mobilized inorganic $\mathrm{P}$, the three LMWOAs also released Po rapidly in a short time, and then the release rate slowed down with the increase of time. Organic P was released by deionized water and LMWOAs followed by oxalic acid $(23.69 \mathrm{mg} / \mathrm{kg})>$ citric acid $(23.03 \mathrm{mg} / \mathrm{kg})>$ malic acid $(14.73 \mathrm{mg} / \mathrm{kg})>$ deionized water $(6.19 \mathrm{mg} / \mathrm{kg})$ after 48 hours.

The results showed that the order of $\mathrm{NaHCO}_{3}-\mathrm{Pi}$ was followed by citric acid $>$ oxalic acid $>$ malic acid, while the order of $\mathrm{NaHCO}_{3}-\mathrm{Pt}$ was oxalic acid $>$ citric acid $>$ malic acid (Figure 4). The concentrations of $\mathrm{NaOH}-\mathrm{Pi}, \mathrm{NaOH}-$ $\mathrm{Pt}$, and $\mathrm{HCl}-\mathrm{P}$ decreased in the samples with citric acid, but only HCl-P decreased in the samples with oxalic acid, while the concentrations of $\mathrm{NaOH}-\mathrm{Pi}$ and $\mathrm{HCl}-\mathrm{P}$ decreased in the samples with malic acid. Meanwhile, the variations of organic P were significantly observed than those of inorganic P. Therefore, we thought that the inorganic P mobilized by citric acid mainly comes from $\mathrm{NaOH}-\mathrm{Pt}$, i.e., $\mathrm{P}$ 


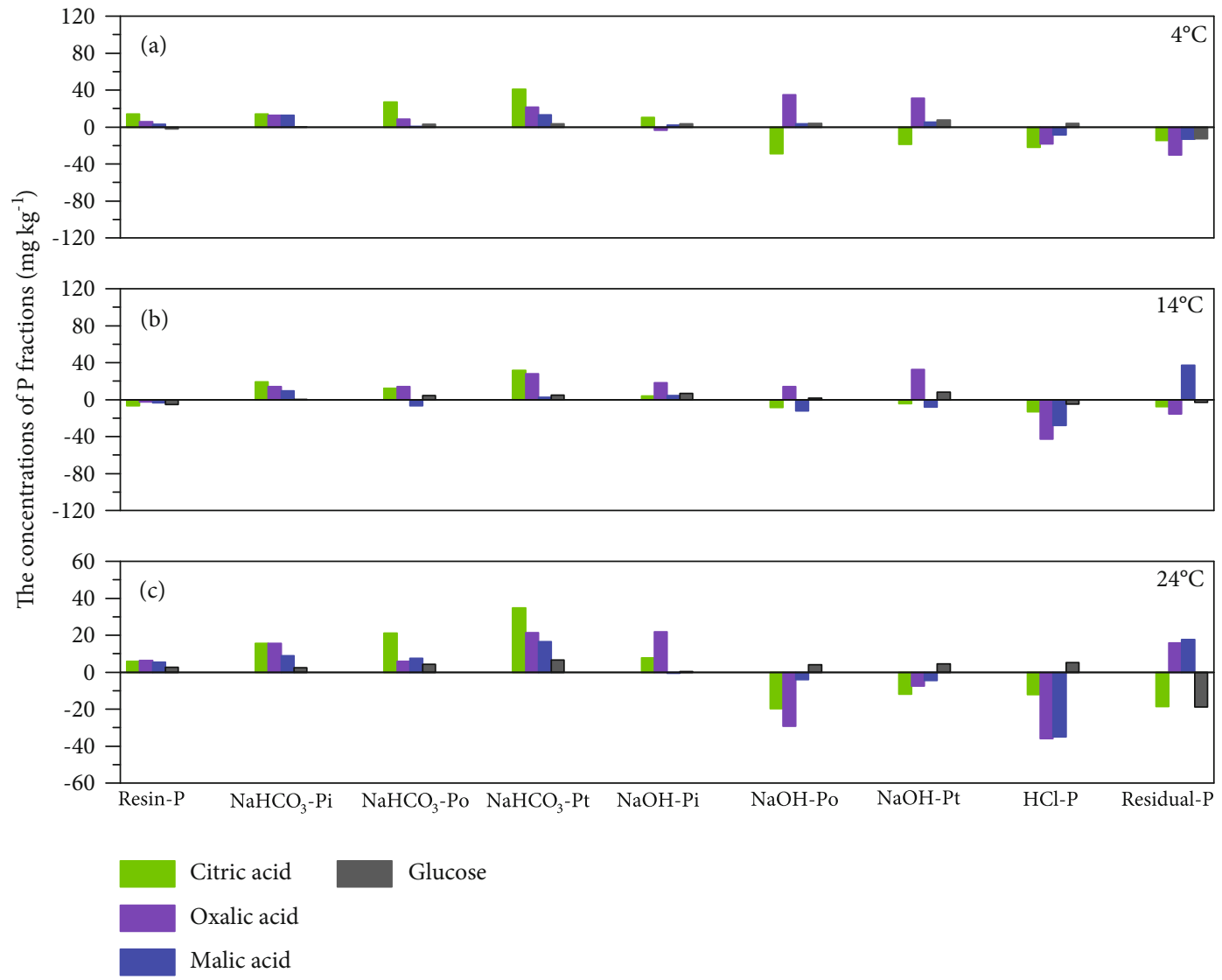

Figure 1: The variations of $\mathrm{P}$ fraction after addition of low molecular weight organic acids (oxalic acid, citric acid, and malic acid) and glucose compared with deionized water at different temperatures $\left((a) 4^{\circ} \mathrm{C}\right.$; (b) $14^{\circ} \mathrm{C}$; (c) $\left.24^{\circ} \mathrm{C}\right)$.

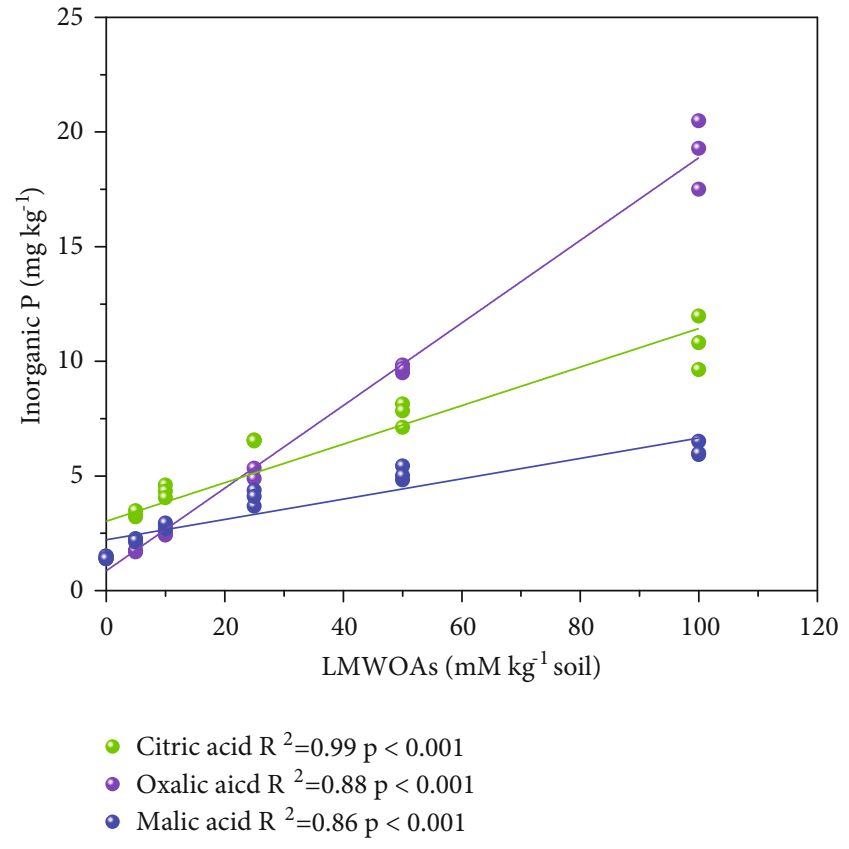

Figure 2: The release of inorganic $\mathrm{P}$ after the addition of different concentrations of low molecular weight organic acids (oxalic acid, citric acid, and malic acid) for one hour. bound to $\mathrm{Fe}$ and $\mathrm{Al}$, while the $\mathrm{P}$ mobilized by oxalic acid and citric acid mainly comes from $\mathrm{HCl}$, i.e., $\mathrm{P}$ bound to $\mathrm{Ca}$.

\section{Discussion}

Consistent with our first hypothesis, we found that LMWOAs had little effect on the fractions of organic $\mathrm{P}$ at lower temperatures when the role of microorganisms was ignored in our study (Figure 1(a)) and significantly changed the $\mathrm{P}$ fraction at higher temperatures (Figure 1(c)). Temperature played an important role in the change of $\mathrm{P}$ fraction by microorganisms. As we all know, LMWOAs can provide energy for microorganisms and affect bioavailable $\mathrm{P}$ through the mineralization of organic $\mathrm{P}$. The results showed that the concentrations of organic $\mathrm{P}$ decreased with the increasing temperature in the process of LMWOAs changing $\mathrm{P}$ fraction, and $\mathrm{NaHCO}_{3}-\mathrm{Po}$ and $\mathrm{NaOH}-\mathrm{Po}$ decreased the most at $24^{\circ} \mathrm{C}$ than those at the other two temperatures. The main reason may be that LMWOAs promoted the activity of soil microorganisms at higher temperatures, and a part of organic $\mathrm{P}$ could be transformed into available inorganic $\mathrm{P}$ by microbial mineralization, leading to the increase of the fraction of inorganic $\mathrm{P}$ [23]. The transformation from organic $\mathrm{P}$ into inorganic $\mathrm{P}$ by mineralization was the main reason for the increasing concentrations of resin- $\mathrm{P}$ and $\mathrm{NaHCO}_{3}$-Pi $[24,25]$, which was consistent with the transformation mechanism of $\mathrm{P}$ fractions in this study. Compared 


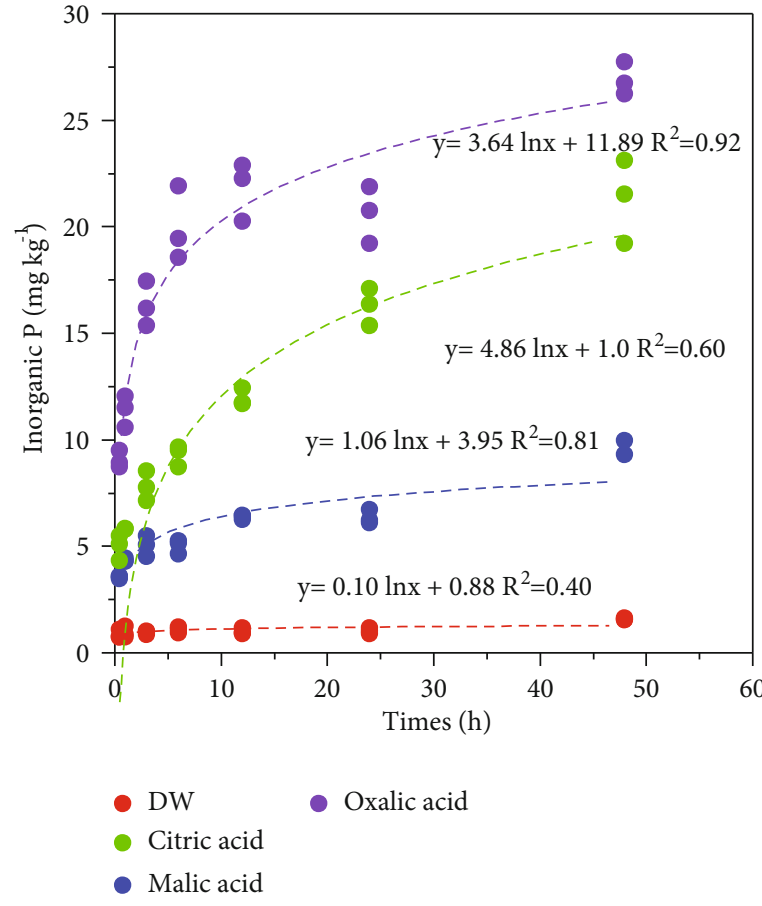

(a)

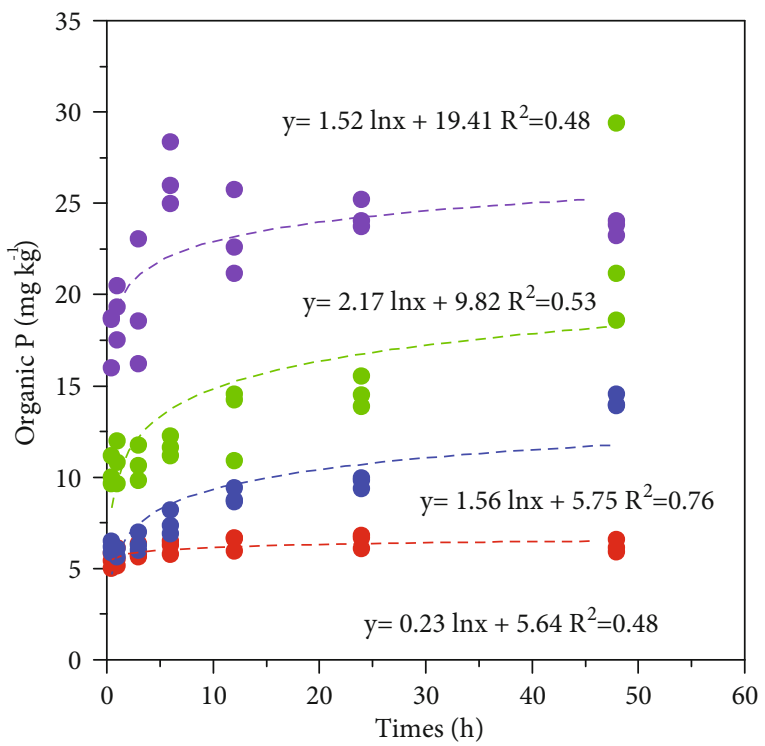

(b)

Figure 3: The kinetics of inorganic $\mathrm{P}(\mathrm{Pi}, \mathrm{a})$ and organic $\mathrm{P}(\mathrm{Po}, \mathrm{b})$ release by water, oxalic acid, citric acid, and malic acid at $100 \mathrm{mmol} \mathrm{kg}^{-1}$ soil from the acidic forest soils. DW: deionized water.

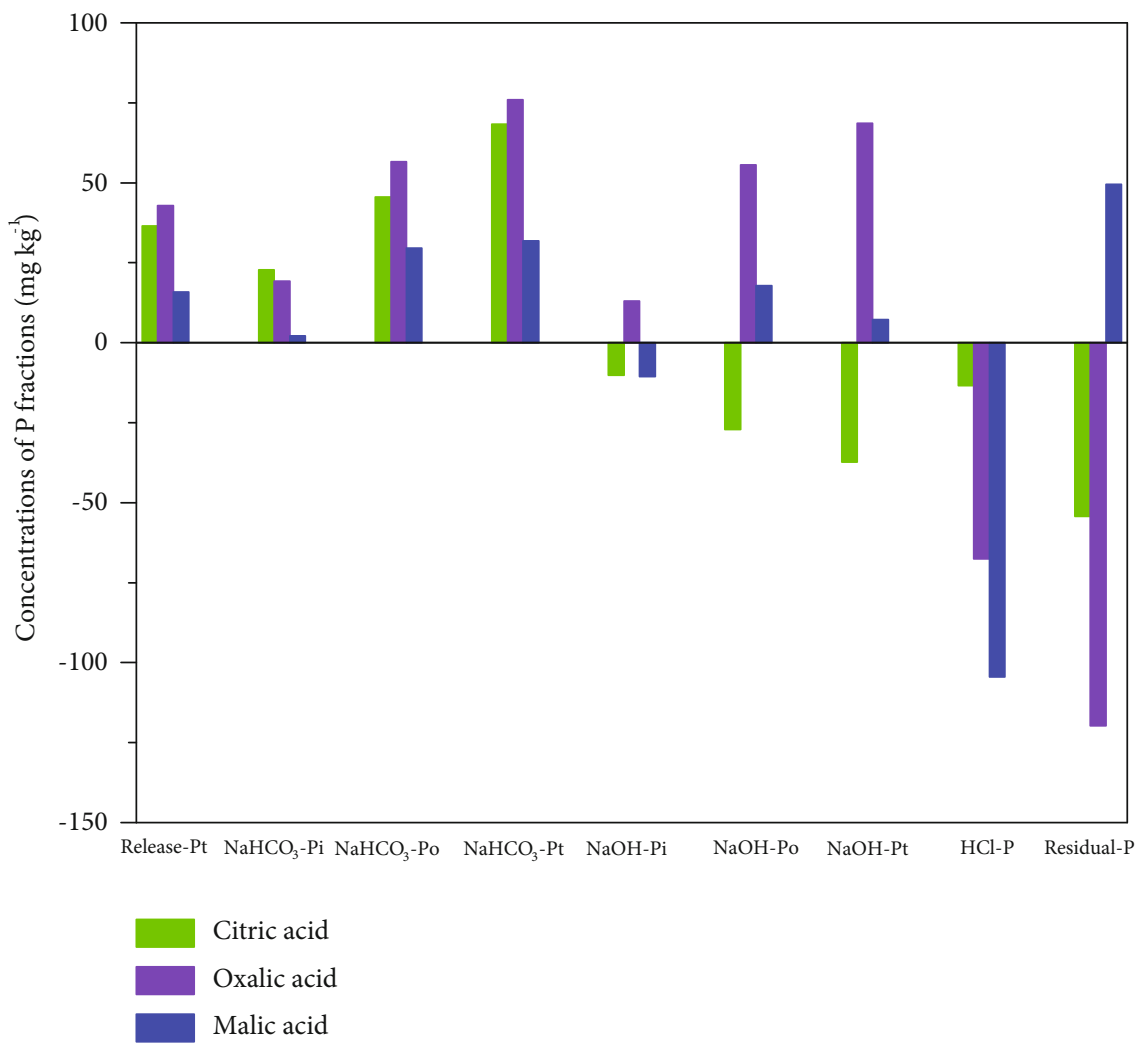

Figure 4: The variations of $\mathrm{P}$ fraction after addition of low molecular weight organic acids (oxalic acid, citric acid, and malic acid) compared with deionized water after 2880 minutes. 
with the other two acids, malic acid had a weaker effect on the $\mathrm{P}$ fraction at the same temperature. Meanwhile, although glucose also could be used as a microbial carbon source, the varied mechanism of $\mathrm{P}$ fraction by glucose at three temperatures was consistent. Glucose did not significantly change the concentration of organic P in soil compared with citric and oxalic acids, meaning that oxalic and citric acids were more easily used by microorganisms than malic acid and glucose to affect the release of organic $P$ [26].

Temperature affects the release of organic $\mathrm{P}$ not only through microorganisms. Our results showed that different kinds of LMWOAs had different effects on $\mathrm{P}$ fractions at lower temperatures through their own (Table 1; Figures 1(a) and 1(b)). For instance, the mechanism of oxalic acid was different from that of citric acid in our study. We found that oxalic acid reduced HCl-P (Ca-P) and residual $\mathrm{P}$ at $4^{\circ} \mathrm{C}$ and $14^{\circ} \mathrm{C}$, while citric acid mainly reduced $\mathrm{NaOH}$ $\mathrm{P}$ (Fe/Al-P) at two temperatures to increase the concentrations of Bio-P. Consequently, these results indicated that the effects of oxalic and citric acids on the change of $P$ fraction were different in alkaline and acidic soils, respectively. Although some studies have shown that the dissolution mechanism of organic $\mathrm{P}$ is similar to that of inorganic $\mathrm{P}$ $[25,27]$, Wei et al. indicated that a concentration of $10 \mathrm{mM}$ citric acid significantly increased the concentration of organic P in forest soils in subtropical and tropical Australia (Table 1), but did not show the effective mobilization of inorganic P [10]. By contrast, LMWOAs seem to be effective in the release of Po as Pi in our study. Different starting substrates of organic $\mathrm{P}$ may be the main reason for this phenomenon (Table 1) [24], and the change of temperature would affect the adsorption/desorption and precipitation/ dissolution of $\mathrm{P}$.

Consistent with our second hypothesis, LMWOAs would increase the rate of the kinetics of both $\mathrm{Pi}$ and $\mathrm{Po}$ release, which was supported by the higher Pi and Po kinetic parameters in LMWOAs than water in our study (Figures 2 and 3). Many studies have demonstrated the potential of LMWOAs to dissolve mineral $\mathrm{P}$ in soil $[8,9,28]$, and LMWOAs significantly changed the $\mathrm{P}$ fractions and improved the Bio-P in acidic, neutral, and alkaline soils. The solubility of soil P was mainly controlled by adsorption/desorption and precipitation/dissolution [2], which were affected by soil physicochemical properties (such as soil $\mathrm{pH}$ ) and biological activities (such as biological fixation, secretions of LMWOAs, and phosphatase) [4, 29-31]. Citric, malic, and oxalic acids could be obtained from plant roots and soil microorganisms to cope with P deficiency $[9,31$, 32]. LMWOAs in the soil were the important substances to improve the soluble of $\mathrm{P}$ and the concentrations of Bio-P in soil.

The different types and concentrations of LMWOAs dominated the $\mathrm{P}$ released through carboxyl groups in most studies, and the different types of LMWOAs had different mobilizing abilities of $\mathrm{P}$ in soil (Table 1). LMWOAs may influence the solubility of $\mathrm{P}$ in soil through direct ligand exchange with phosphate, and ligand promotes mineral dissolution $[10,28,32,33]$. Hence, the mobilization ability of LMWOAs was followed by ternary carboxylic acid > binary carboxylic acid $>$ monocarboxylic acid. Ternary carboxylic acids (such as citric acid) were generally more capable of dissolving inorganic $\mathrm{P}$ than binary carboxylic acids (such as oxalic acid) and monocarboxylic acids [33,34]. Although the carboxyl number of oxalic acid (dicarboxylic acid) was less than that of citric acid (ternary carboxylic acid), the existing research showed that oxalic acid is stronger than citric acid in the process of $\mathrm{P}$ mobilization due to the buffering capacity of the forest soils. The mobilization ability of oxalic acid was also stronger than citric and malic acids in our study when the concentration of oxalic acid was enough high (Figures 2 and 3). Hence, the number of carboxyl groups in soil solution was the decisive factor to determine the transformation of $\mathrm{P}$ fractions. Consequently, the higher concentration of LMWOAs means that more carboxyl groups can be exchanged by metal cations. The concentrations of dissolved inorganic P fractions by LMWOAs usually increased with the increasing concentration of LMWOAs. However, there may be a critical threshold for the concentration of LMWOAs required for the solution of adsorbed and precipitated $P[26,35]$. In our study, citric acid could mobilize more $\mathrm{P}$ at a lower concentration than oxalic acid. However, when the concentration of LMWOAs was more than $25 \mathrm{mM}$, oxalic acid could mobilize more Ca-P, while citric acid had a weak mobilize ability to Ca-P compared with oxalic acid. As in other studies, the mobilization of Ca-P by oxalic acid was more significant in alkaline soils or high apatite soils [35]. Therefore, the results showed the order of $\mathrm{P}$ mobilization was oxalic acid $>$ citric acid $>$ malic acid in our study when the concentration of LMWOAs was more than $25 \mathrm{mM}$. This result also explained why citric acid had a significant effect on Bio-P in the rhizosphere soil in Mt. Gongga, but oxalic acid was not significant in acidic soil [20]. In all, both the concentrations and types of LMWOAs affect the concentrations and transformation of inorganic $\mathrm{P}$ fractions.

As the mobilization capacity of LMWOAs increased with time, more stable $\mathrm{P}$ was mobilized to liable $\mathrm{P}$ fractions. Our results showed that LMWOAs tend to mobilize stable $\mathrm{P}$ fractions to liable $\mathrm{P}$ fractions (Figure 4). The concentrations of released $\mathrm{Pi}$ and Po from stable P fractions in soil increase rapidly during the first 5 to $240 \mathrm{~min}$ of the kinetic study and then plateaued as an apparent equilibrium was reached. This two-phase pattern of initially rapid $\mathrm{P}$ release followed by slower release was reported by other reports [36-38] and was attributed to a combination of dissolution and desorption process. In this study, the fraction of $\mathrm{NaHCO}_{3}-\mathrm{Pi}$ tended to increase after releasing $\mathrm{Pi}$ into the soil solution with the addition of LMWOAs. There was a fast first and slow reaction process for the release of Bio-P by LMWOAs in nonlime soil $[24,27]$. Consequently, the Bio-P in the soil was also released rapidly within one hour after LMWOAs were added to the soil, and then the release rate gradually slowed down in our study (Figure 2).

LMWOAs could make stable $\mathrm{P}$ fractions (Fe/Al-P and $\mathrm{Ca}-\mathrm{P})$ transformed to liable $\mathrm{P}\left(\mathrm{NaHCO}_{3}-\mathrm{P}\right.$ and resin- $\left.\mathrm{P}\right)$. Our results showed that the $\mathrm{pH}$ in the solution increases gradually with the increase of time and $\mathrm{P}$ release, which means that the $\mathrm{H}^{+}$in the solution decreases (Figure S2). 
TABLE 1: The variations of $\mathrm{P}$ fractions induced by organic acids compared with other reports.

\begin{tabular}{|c|c|c|c|c|c|c|c|c|c|c|c|}
\hline Soil type & $\begin{array}{c}\text { Concentrations } \\
(\mathrm{mM})\end{array}$ & Area & $\begin{array}{l}\text { Organic } \\
\text { acids }\end{array}$ & $\begin{array}{c}\text { Soluble- } \\
\mathrm{Pi}\end{array}$ & $\begin{array}{c}\text { Soluble } \\
\text {-Po }\end{array}$ & $\begin{array}{c}\mathrm{NaHCO}_{3-}^{-} \\
\mathrm{Pi} \\
\end{array}$ & $\begin{array}{c}\mathrm{NaHCO}_{3-}^{-} \\
\text {Po } \\
\end{array}$ & $\begin{array}{c}\mathrm{NaOH}- \\
\mathrm{Pi}\end{array}$ & $\begin{array}{c}\mathrm{NaOH}- \\
\mathrm{Po}\end{array}$ & $\begin{array}{c}\mathrm{HCl}- \\
\mathrm{P} \\
\end{array}$ & Reference \\
\hline \multirow{3}{*}{ Acid soil } & \multirow{3}{*}{100} & \multirow{3}{*}{$\begin{array}{l}\text { Southwest } \\
\text { China }\end{array}$} & Citric acid & $\uparrow$ & $\uparrow$ & $\uparrow$ & $\uparrow$ & $\downarrow$ & $\downarrow$ & $\downarrow$ & \multirow{3}{*}{$\begin{array}{l}\text { This } \\
\text { study }\end{array}$} \\
\hline & & & $\begin{array}{c}\text { Oxalic } \\
\text { acid }\end{array}$ & $\uparrow$ & $\uparrow$ & $\uparrow$ & $\uparrow$ & $\uparrow$ & $\uparrow$ & $\downarrow$ & \\
\hline & & & Malic acid & $\uparrow$ & $\uparrow$ & $\uparrow$ & $\uparrow$ & $\downarrow$ & $\uparrow$ & $\downarrow$ & \\
\hline \multirow{3}{*}{ Acid soil } & & \multirow{9}{*}{$\begin{array}{l}\text { Northeast } \\
\text { China }\end{array}$} & Citric acid & ns & ns & - & $\downarrow$ & $\downarrow$ & - & - & \multirow{9}{*}[24]{} \\
\hline & & & $\begin{array}{l}\text { Oxalic } \\
\text { acid }\end{array}$ & ns & ns & - & - & - & - & - & \\
\hline & & & Malic acid & ns & ns & - & - & - & - & - & \\
\hline \multirow{3}{*}{$\begin{array}{l}\text { Neutral } \\
\text { soil }\end{array}$} & \multirow{3}{*}{10} & & Citric acid & ns & ns & - & $\downarrow$ & - & - & - & \\
\hline & & & $\begin{array}{c}\text { Oxalic } \\
\text { acid }\end{array}$ & ns & ns & - & - & - & - & - & \\
\hline & & & Malic acid & ns & ns & - & - & - & - & - & \\
\hline \multirow{3}{*}{$\begin{array}{l}\text { Alkaline } \\
\text { soil }\end{array}$} & & & Citric acid & ns & ns & - & - & - & - & - & \\
\hline & & & $\begin{array}{c}\text { Oxalic } \\
\text { acid }\end{array}$ & ns & ns & - & - & - & - & - & \\
\hline & & & Malic acid & ns & ns & - & - & - & - & - & \\
\hline \multirow{3}{*}{ Acid soil } & \multirow{3}{*}{10} & \multirow{3}{*}{ Australia } & Citric acid & - & $\uparrow$ & ns & ns & ns & ns & ns & \multirow{3}{*}[10]{} \\
\hline & & & $\begin{array}{l}\text { Oxalic } \\
\text { acid }\end{array}$ & - & $\uparrow$ & ns & ns & ns & ns & ns & \\
\hline & & & Malic acid & - & - & ns & ns & ns & ns & ns & \\
\hline \multirow{3}{*}{$\begin{array}{l}\text { Alkaline } \\
\text { soil }\end{array}$} & \multirow{3}{*}{100} & \multirow{3}{*}{ East China } & Citric acid & $\uparrow$ & ns & $\downarrow$ & $\downarrow$ & $\downarrow$ & - & $\downarrow$ & \multirow{3}{*}[41]{} \\
\hline & & & $\begin{array}{c}\text { Oxalic } \\
\text { acid }\end{array}$ & $\uparrow$ & ns & - & $\uparrow$ & $\downarrow$ & - & $\downarrow$ & \\
\hline & & & Malic acid & $\uparrow$ & ns & $\downarrow$ & $\uparrow$ & - & - & $\downarrow$ & \\
\hline \multirow{3}{*}{ Acid soil } & \multirow{3}{*}{1} & \multirow{3}{*}{ South China } & Citric acid & $\uparrow$ & $\uparrow$ & ns & ns & ns & ns & ns & \multirow{3}{*}{ [5] } \\
\hline & & & $\begin{array}{c}\text { Oxalic } \\
\text { acid }\end{array}$ & $\uparrow$ & $\uparrow$ & ns & ns & ns & ns & ns & \\
\hline & & & Malic acid & - & - & ns & ns & ns & ns & ns & \\
\hline
\end{tabular}

Note: ns means no data; $\uparrow$ or $\downarrow$ means increase or decrease relative to control; - means no significant variation.

The reason was that $\mathrm{H}^{+}$in LMWOAs occupied the adsorption sites of the original $\mathrm{Fe} / \mathrm{Al}$ or $\mathrm{Ca}$ by reacting with $\mathrm{Fe} / \mathrm{Al}$ or $\mathrm{Ca}$ in the soil, which complexes with $\mathrm{COOH}^{-}$or chelates, thus, realizing the mineral-bound $\mathrm{P}$ fraction and increasing concentration of Bio- $\mathrm{P}$. When $\mathrm{pH}=4.0$, citric acid can form stable compounds with $\mathrm{Fe}^{3+}$, which promotes the release of $\mathrm{P}$ from Fe-P. When $\mathrm{pH}$ is less than 4.0, LMWOAs can mobilize Ca-P effectively. In this study, the $\mathrm{pH}$ after the LMWOAs was added is less than or equal to 4.0. Therefore, the soil in the Gongga Mountain could effectively liberate both Fe-P and Ca-P in the soil after $10 \mathrm{mM}$ LMWOAs were added. The significant variations of $\mathrm{pH}$ value in oxalic acid during the initial rapid phase were further to confirm that the sources of $\mathrm{Pi}$ and $\mathrm{Po}$ in the solution were $\mathrm{HCl}-\mathrm{P}(\mathrm{Ca}-$ $\mathrm{P})$ or $\mathrm{NaOH}-\mathrm{Pi}(\mathrm{Fe} / \mathrm{Al}-\mathrm{Pi})$ by the end of the kinetic experiment, indicating the dissolution of mineral-bound $\mathrm{P}$ compounds occurred when the soil was treated with LMWOAs.

Although LMWOAs could make stable P fractions (Fe/ Al-P and $\mathrm{Ca}-\mathrm{P})$ transformed to liable $\mathrm{P}\left(\mathrm{NaHCO}_{3}-\mathrm{P}\right.$ and resin-P), we found that this rule is not completely consistent with the transformation process. The possible reason was that although LMWOAs can liberate part of the stable P, there was also adsorption on the particle surface, which made part of the $\mathrm{P}$ fixed again because of the high soil organic matter $[24,39]$. In addition, we found that the concentration of resin-P increased significantly after LMWOAs were added, and resin-P was the most easily absorbed and utilized by plants in the soil. This also proved that LMWOAs secreted by roots increase Bio-P according to their growth requirements $[31,40]$. Therefore, the production of LMWOAs by plants in the rhizosphere was an important mechanism to improve Bio-P in soil, mainly because LMWOAs significantly increase the concentration of resin$\mathrm{P}$ and then increase the concentration of Bio-P absorbed by plants. In conclusion, the concentration of Bio-P in the soil was increased due to partial chelation and dissolution of phosphate in the main $\mathrm{Fe} / \mathrm{Al}$ binding. The release of Bio-P by LMWOAs in acid soil was mainly through the reduction and dissolution of $\mathrm{Fe} / \mathrm{Al}$ and $\mathrm{Ca}$, or the subsequent release of $\mathrm{P}$ bound or enclosed in the $\mathrm{Fe} / \mathrm{Al}$ and $\mathrm{Ca}$ $[5,39]$. 


\section{Conclusion}

The addition of low molecular weight organic acids increased both the concentration and rate of the kinetics of inorganic $\mathrm{P}$ and organic $\mathrm{P}$ release in acidic forest soils. Low molecular weight organic acids were more easily used by microorganisms than glucose to affect the release of $\mathrm{P}$ through the mineralization of more organic P. However, removing the effects of microorganisms, the Po released upon treatment with low molecular weight organic acids represented half of the total $\mathrm{P}$ released, which promoted the understanding of the mechanisms of organic $\mathrm{P}$ release in the presence of low molecular weight organic acids, while the enhanced inorganic P release was likely due to the accelerated desorption and dissolution process. Fractions of inorganic $\mathrm{P}$ and organic $\mathrm{P}$ were greater when soils were treated with oxalic acid than those with the other organic acids when the concentrations of low molecular weight organic acids were greater than $25 \mathrm{mM}$. Future research should highlight the sources and consumption of low molecular weight organic acids effects on the availability and transformation of soil $\mathrm{P}$ to better understand the biogeochemical cycling of $\mathrm{P}$ and the underlying mechanisms in different ecosystems.

\section{Data Availability}

We provide our data in the Supplementary Information files to support the conclusions of our study.

\section{Conflicts of Interest}

All authors in this manuscript have directly participated in the planning, execution, and/or data analysis of this study, and we have no conflicts of interest in this work. We declare that the manuscript was not published or under review elsewhere. And we also declare that we do not have any commercial or associative interest that represents a conflict of interest in connection with the work submitted.

\section{Acknowledgments}

This study was supported by the National Natural Science Foundation of China (41630751), the Youth Science Foundation of Institute of Mountain Hazards and Environment, Chinese Academy of Sciences (SDS-QN-2105), and the Key Research and Development program of Sichuan Province, China (2018JZ0075).

\section{Supplementary Materials}

Figure S1: the concentrations of $\mathrm{P}$ fractions after addition with deionized water (ck), the organic acids, and glucose solution in acidic forest soils. Figure S2: the variations of suspensions $\mathrm{pH}$ after addition with deionized water (ck) and the organic acids with in acidic forest soils. (Supplementary Materials)

\section{References}

[1] L. Augusto, D. L. Achat, M. Jonard, D. Vidal, and B. Ringeval, "Soil parent material-a major driver of plant nutrient limita- tions in terrestrial ecosystems," Global Change Biology, vol. 23, no. 9, pp. 3808-3824, 2017.

[2] E. Frossard, L. M. Condron, A. Oberson, S. Sinaj, and J. C. Fardeau, "Processes governing phosphorus availability in temperate soils," Journal of Environmental Quality, vol. 29, no. 1, pp. 15-23, 2000.

[3] E. Q. Hou, C. R. Chen, Y. W. Kuang, Y. G. Zhang, M. Heenan, and D. Z. Wen, "A structural equation model analysis of phosphorus transformations in global unfertilized and uncultivated soils," Global Biogeochemical Cycles, vol. 30, no. 9, pp. 13001309, 2016.

[4] P. M. Vitousek, S. Porder, B. Z. Houlton, and O. A. Chadwick, "Terrestrial phosphorus limitation: mechanisms, implications, and nitrogen-phosphorus interactions," Ecological Applications, vol. 20, no. 1, pp. 5-15, 2010.

[5] E. Q. Hou, S. B. Tang, C. R. Chen et al., "Solubility of phosphorus in subtropical forest soils as influenced by low- molecular organic acids and key soil properties," Geoderma, vol. 313, pp. 172-180, 2018.

[6] F. Yang, L. Sui, C. Y. Tang, J. S. Li, K. Cheng, and Q. Xue, "Sustainable advances on phosphorus utilization in soil via addition of biochar and humic substances," Science of the Total Environment, vol. 768, article 145106, 2021.

[7] S. C. Reed, X. J. Yang, and P. E. Thornton, "Incorporating phosphorus cycling into global modeling efforts: a worthwhile, tractable endeavor," New Phytologist, vol. 208, no. 2, pp. 324329, 2015.

[8] D. L. Jones, P. G. Dennis, A. G. Owen, and P. A. W. van Hees, "Organic acid behavior in soils - misconceptions and knowledge gaps," Plant and Soil, vol. 248, no. 1/2, pp. 31-41, 2003.

[9] R. Adeleke, C. Nwangburuka, and B. Oboirien, "Origins, roles and fate of organic acids in soils: a review," South African Journal of Botany, vol. 108, pp. 393-406, 2017.

[10] L. L. Wei, C. R. Chen, and Z. H. Xu, "Citric acid enhances the mobilization of organic phosphorus in subtropical and tropical forest soils," Biology and Fertility of Soils, vol. 46, no. 7, pp. 765-769, 2010.

[11] P. Chandra Sekhar, F. Mercl, J. Száková, V. Tejnecký, and P. Tlustoš, "The role of low molecular weight organic acids in the release of phosphorus from sewage sludge-based biochar," All Life, vol. 14, no. 1, pp. 599-609, 2021.

[12] A. Andrino, G. Guggenberger, S. Kernchen, R. Mikutta, L. Sauheitl, and J. Boy, "Production of organic acids by arbuscular mycorrhizal fungi and their contribution in the mobilization of phosphorus bound to iron oxides," Frontiers in Plant Science, vol. 12, article 661842, 2021.

[13] P. J. Hocking, "Organic acids exuded from roots in phosphorus uptake and aluminum tolerance of plants in acid soils," Advances in Agronomy, vol. 74, pp. 63-97, 2001.

[14] M. C. Chen, M. K. Wang, C. Y. Chiu, P. M. Huang, and H. B. King, "Determination of low molecular weight dicarboxylic acids and organic functional groups in rhizosphere and bulk soils of Tsuga and Yushania in a temperate rain forest," Plant and Soil, vol. 231, no. 1, pp. 37-44, 2001.

[15] B. L. Turner, L. M. Condron, S. J. Richardson, D. A. Peltzer, and V. J. Allison, "Soil organic phosphorus transformations during pedogenesis," Ecosystems, vol. 10, no. 7, pp. 11661181, 2007.

[16] K. Xiao, H. Katagi, M. Harrison, and Z. Y. Wang, "Improved phosphorus acquisition and biomass production in _Arabidopsis_by transgenic expression of a purple acid phosphatase 
gene from_M. truncatula_," Plant Science, vol. 170, no. 2, pp. 191-202, 2006.

[17] A. Oral and V. Uygur, "Effects of low-molecular-mass organic acids on $\mathrm{P}$ nutrition and some plant properties ofHordeum vulgare," Journal of Plant Nutrition, vol. 41, no. 11, pp. 1482-1490, 2018.

[18] J. Zhou, Y. H. Wu, H. J. Bing et al., "Variations in soil phosphorus biogeochemistry across six vegetation types along an altitudinal gradient in SW China," Catena, vol. 142, pp. 102111, 2016.

[19] H. J. Bing, Y. H. Wu, J. Zhou et al., "Stoichiometric variation of carbon, nitrogen, and phosphorus in soils and its implication for nutrient limitation in alpine ecosystem of Eastern Tibetan Plateau," Journal of Soils and Sediments, vol. 16, no. 2, pp. 405-416, 2016.

[20] H. Zhu, H. J. Bing, Y. H. Wu, H. Y. Sun, and J. Zhou, "Low molecular weight organic acids regulate soil phosphorus availability in the soils of subalpine forests, eastern Tibetan Plateau," Catena, vol. 203, article 105328, 2021.

[21] M. J. Hedley and J. W. B. Stewart, "Method to measure microbial phosphate in soils," Soil Biology \& Biochemistry, vol. 14, no. 4, pp. 377-385, 1982.

[22] J. Murphy and J. P. Riley, "Citation-classic - a modified single solution method for the determination of phosphate in natural-waters," Current Contents/Agriculture Biology \& Environmental Sciences, vol. 1986, no. 12, p. 16, 1986.

[23] R. A. Bowman and C. V. Cole, "Transformations of organic phosphorus substrates in soils as evaluated by Nahco3 extraction," Soil Science, vol. 125, no. 1, pp. 49-54, 1978.

[24] Y. Z. Wang, X. Chen, J. K. Whalen et al., "Kinetics of inorganic and organic phosphorus release influenced by low molecular weight organic acids in calcareous, neutral and acidic soils," Journal of Plant Nutrition and Soil Science, vol. 178, no. 4, pp. 555-566, 2015.

[25] Y. Z. Wang, J. K. Whalen, X. Chen et al., "Mechanisms for altering phosphorus sorption characteristics induced by lowmolecular-weight organic acids," Canadian Journal of Soil Science, vol. 96, no. 3, pp. 289-298, 2016.

[26] D. Menezes-Blackburn, C. Paredes, H. Zhang et al., "Organic acids regulation of chemical microbial phosphorus transformations in soils," Environmental Science \& Technology, vol. 50, no. 21, pp. 11521-11531, 2016.

[27] Y. Z. Wang, X. Chen, C. Y. Lu, B. Huang, and Y. Shi, "Different mechanisms of organic and inorganic phosphorus release from Mollisols induced by low molecular weight organic acids," Canadian Journal of Soil Science, vol. 98, no. 1, pp. 15-23, 2017.

[28] E. Oburger, G. J. D. Kirk, W. W. Wenzel, M. Puschenreiter, and D. L. Jones, "Interactive effects of organic acids in the rhizosphere," Soil Biology \& Biochemistry, vol. 41, no. 3, pp. 449457, 2009.

[29] M. Clarholm, U. Skyllberg, and A. Rosling, "Organic acid induced release of nutrients from metal-stabilized soil organic matter - the unbutton model," Soil Biology \& Biochemistry, vol. 84, pp. 168-176, 2015.

[30] A. E. Richardson, P. J. Hocking, R. J. Simpson, and T. S. George, "Plant mechanisms to optimise access to soil phosphorus," Crop \& Pasture Science, vol. 60, no. 2, pp. 124-143, 2009.

[31] D. L. Jones, "Organic acids in the rhizosphere - a critical review,” Plant and Soil, vol. 205, no. 1, pp. 25-44, 1998.
[32] C. N. Guppy, N. W. Menzies, P. W. Moody, and F. P. C. Blamey, "Competitive sorption reactions between phosphorus and organic matter in soil, a review," Australian Journal of Soil Research, vol. 43, no. 2, pp. 189-202, 2005.

[33] E. Oburger, D. Leitner, D. L. Jones, K. C. Zygalakis, A. Schnepf, and T. Roose, "Adsorption and desorption dynamics of citric acid anions in soil," European Journal of Soil Science, vol. 62, no. 5, pp. 733-742, 2011.

[34] N. S. Bolan, R. Naidu, S. Mahimairaja, and S. Baskaran, "Influence of low-molecular-weight organic-acids on the solubilization of phosphates," Biology and Fertility of Soils, vol. 18, no. 4, pp. 311-319, 1994.

[35] H. L. Lu, C. L. Yan, and J. C. Liu, "Low-molecular-weight organic acids exuded by Mangrove (_Kandelia candel_(L.) Druce) roots and their effect on cadmium species change in the rhizosphere," Environmental and Experimental Botany, vol. 61, no. 2, pp. 159-166, 2007.

[36] J. De Smet, J. Vanderdeelen, and G. Hofman, "Effect of soil properties on the kinetics of phosphate release," Communications in Soil Science and Plant Analysis, vol. 29, no. 11-14, pp. 2135-2147, 1998.

[37] M. Jalali and S. S. Tabar, "Chemical fractionation of phosphorus in calcareous soils of Hamedan, western Iran under different land use," Journal of Plant Nutrition and Soil Science, vol. 174, no. 4, pp. 523-531, 2011.

[38] M. Jalali and N. A. M. Zinli, "Kinetics of phosphorus release from calcareous soils under different land use in Iran," Journal of Plant Nutrition and Soil Science, vol. 174, no. 1, pp. 38-46, 2011.

[39] J. X. Zhang, L. Gao, Z. D. Pang et al., "Effect of low-molecularweight organic acids on phosphorus soil activation: a laboratory study of the soils from Wangbeng section of the Huaihe River Basin, China," Plant, Soil and Environment, vol. 67, no. 11, pp. 660-667, 2021.

[40] Z. Khademi, D. L. Jones, M. J. Malakouti, and F. Asadi, "Organic acids differ in enhancing phosphorus uptake by Triticum aestivum L.-effects of rhizosphere concentration and counterion," Plant and Soil, vol. 334, no. 1-2, pp. 151-159, 2010.

[41] G. Xu, H. B. Shao, X. R. Fu et al., "The role of root-released organic acids and anions in phosphorus transformations in a sandy loam soil from Yantai, China," African Journal of Microbiology Research, vol. 6, no. 3, pp. 674-679, 2012. 